\title{
Differential Synaptic Integration of Interneurons in the Outer and Inner Molecular Layers of the Developing Dentate Gyrus
}

\author{
Ramesh Chittajallu, ${ }^{1}$ Albrecht Kunze, ${ }^{1,2}$ Jean-Marie Mangin, ${ }^{1}$ and Vittorio Gallo ${ }^{1}$ \\ ${ }^{1}$ Center for Neuroscience Research, Children's National Medical Center, Washington, DC 20010, and 2Department of Neurology, University of Jena, 07747 \\ Jena, Germany
}

The dentate gyrus (DG) undergoes continued reorganization and lamination during early postnatal development. Interneurons with anatomically identified synaptic contacts migrate from the outer to the inner regions of the molecular layer (ML) of the DG. By using the $2^{\prime}, 3^{\prime}$-cyclic nucleotide $3^{\prime}$-phosphodiesterase (CNP)-enhanced green fluorescent protein transgenic mouse, we were able to target and physiologically characterize Dlx $2^{+}$developing ML interneurons. We investigated whether synapses on migrating ML interneurons were functional and defined properties of synaptic inputs onto interneurons that were located in the outer ML (OML) or inner ML (IML). Consistent with ongoing maturation, IML interneurons displayed lower input resistances and more hyperpolarized resting membrane potentials than OML interneurons. Both OML and IML interneurons received a direct excitatory monosynaptic input from the entorhinal cortex via the perforant paths, but this input was differentially sensitive to activation of presynaptic group II and III metabotropic glutamate receptors. Furthermore, only IML interneurons also received significant synaptic input from the CA3/hilar region, especially under conditions of experimentally induced disinhibition. These changes are attributed to a significant reorganization of dendritic fields. $\mathrm{GABA}_{\mathrm{A}}$ receptor-mediated innervation of OML and IML interneurons also displayed significant differences in miniature IPSC amplitude, frequency, and decay kinetics. Finally, cell-attached recordings indicated that $\mathrm{GABA}_{\mathrm{A}}$ receptor activation was depolarizing in OML interneurons but predominantly shunting in IML interneurons. Our data provide evidence that developing ML interneurons receive functional glutamatergic and GABAergic inputs and undergo significant changes in synaptic integration during migration from the OML to the IML.

Key words: $\mathrm{CNP}$-expressing progenitors; cell migration; hippocampus; synaptic transmission; $\mathrm{GABA}_{\mathrm{A}}$ receptors; presynaptic regulation

\section{Introduction}

Although the vast majority of inhibitory neurons are born during embryonic developmental stages, migration, maturation, and plasticity in the postnatal brain represent ongoing processes essential for appropriate synaptic integration. A number of studies have highlighted developmentally regulated modifications in functional aspects of inhibitory neurotransmission in the postnatal CNS (Ben Ari, 2002; Plotkin et al., 2005; Daw et al., 2007).

Hippocampal interneurons are diverse and present in all hip-

Received April 16, 2007; accepted June 20, 2007.

This work was supported by National Institutes of Health (NIH) Grants R01NS045702 (V.G.) and R21NS050463 (V.G.), by Citizens United for Research on Epilepsy (V.G.), and by NIH Grant MRDDRC P30HD40677. R.C. and V.G. were responsible for conceptual development of the study. R.C. was involved in the design of the experiments and attained the immunocytochemical and physiological data presented. A.K. was responsible for initial pilot experiments leading to the current study and was additionally funded by an Interdisziplinäres Zentrum für Klinische Forschung Jena Fellowship (TP 1.7). J.-M.M. provided suggestions for experimental design and additional conceptual advice. We thank Chris McBain and Josh Corbin for critical comments on this manuscript. We thank Dr. Kazuaki Yoshikawa (Institute of Protein Research, 0saka University, Osaka, Japan) for the gift of anti-Dlx2 antibodies.

Correspondence should be addressed to Vittorio Gallo, Center for Neuroscience Research, Children's Research Institute, Children's National Medical Center, Washington, DC 20010. E-mail: vgallo@enmcresearch.org. DOI:10.1523/JNEUROSCI.2476-07.2007

Copyright $\odot 2007$ Society for Neuroscience $\quad 0270-6474 / 07 / 278219-07 \$ 15.00 / 0$ pocampal subfields, but little is known about the function of those residing in the molecular layer $(\mathrm{ML})$ of the dentate gyrus (DG). These interneurons continue to migrate in the postnatal hippocampus from the outer ML (OML) to the inner ML (IML), en route to the granule cell layer (GCL) and hilar regions, during the first two postnatal weeks (Dupuy-Davies and Houser, 1999; Morozov and Freund, 2003). Interestingly, light and electron microscopic analyses have demonstrated that these developing interneurons possess synaptic connections during this relocation (Morozov et al., 2006). This observation represents a novel mode of cellular migration. Nevertheless, anatomical approaches alone cannot definitively demonstrate whether synapses on migrating interneurons are functional and, if so, what the neurotransmitter released at these synapses is and from which regions these synaptic inputs originate.

In the current study, we show that the $2^{\prime}, 3^{\prime}$-cyclic nucleotide $3^{\prime}$-phosphodiesterase (CNP)-enhanced green fluorescent protein (EGFP) mouse can be used to (1) identify these synaptically connected ML interneurons that undergo migration and (2) functionally characterize their synaptic inputs. We compare and contrast varying aspects of excitatory and inhibitory transmission onto these developing interneurons in the OML and IML and demonstrate significant alterations in the synaptic integration during this postnatal migratory program. 


\section{Materials and Methods}

Materials. The CNP-EGFP mouse has been described previously (Yuan et al., 2002). Animal procedures were performed according to the DC Children's Hospital Institutional Animal Care and Use Committee and National Institutes of Health guidelines. All reagents were from Sigma-Aldrich (St. Louis, MO) or Tocris Bioscience (Ellisville, MO). Antibodies used are listed in supplemental Table 1 (available at www. jneurosci.org as supplemental material).

Immunocytochemistry. Floating, frozen 50 $\mu \mathrm{M}$ horizontal hippocampal sections were attained from fixed (4\% paraformaldehyde) postnatal day 9 (P9) CNP-EGFP mice brains. Immunostaining and processing of biocytinfilled, recorded cells were performed as described previously (Belachew et al., 2003; Chittajallu et al., 2004).

Electrophysiology. After anesthetization with isoflurane, horizontal $300 \mu \mathrm{M}$ sections from P6-P12 brains were attained in ice-cold sucrose-based cutting solution (composition in $\mathrm{mm}$ ): $87 \mathrm{NaCl}, 75$ sucrose, $2.5 \mathrm{KCl}, 1.25$ $\mathrm{NaH}_{2} \mathrm{PO}_{4}, 7 \mathrm{MgCl}_{2}, 0.5 \mathrm{CaCl}_{2}, 25 \mathrm{NaHCO}_{3}$, and 25 glucose. Slices were warmed to $35^{\circ} \mathrm{C}$ in the same solution for $30 \mathrm{~min}$ and then to a holding chamber containing extracellular solution (Chittajallu et al., 2005). After $1 \mathrm{~h}$ of recovery, slices were placed in a recording chamber perfused with extracellular solution for whole-cell patch-clamp recordings. Solutions were gassed with $95 \% \mathrm{O}_{2} / 5 \% \mathrm{CO}_{2}$. All recordings were at room temperature from faint $\mathrm{EGFP}^{+}$interneurons with soma located either in the OML or IML with an Axopatch 200B or a Multiclamp 700B amplifier (Molecular Devices, Sunnyvale, CA). Data was digitized and filtered at 5 and 10 $\mathrm{kHz}$, respectively. Detailed descriptions of all of the electrophysiological methods are outlined in the supplemental methods (available at www. jneurosci.org as supplemental material).

\section{Results}

The CNP-EGFP mouse allows

identification of developing

interneurons throughout the

hippocampal ML of the dentate gyrus

Numerous $\mathrm{EGFP}^{+}$cells were present throughout the developing hippocampal ML (Fig. 1A). Based on EGFP intensity and cell morphology, $\mathrm{EGFP}^{+} \mathrm{NG}^{+}$cells $(\mathrm{CNP}$ gene-expressing progenitors) and a population of interneurons $\left(\mathrm{EGFP}^{+} \mathrm{GAD} 65 /\right.$ $67^{+}$) could be easily distinguished (Fig. $1 A, B)$. In the ML, $95 \pm 3 \%$ of the $\mathrm{EGFP}^{+} \mathrm{GAD} 65 / 67^{+}$cells expressed the transcription factor Dlx2 $(n=181$ cells, 15 sections, 3 brains) (Fig. 1C). Orthogonal sections clearly demonstrate GAD65/67 immunoreactivity overlaps with the cytoplasmic EGFP (Fig. 1C). Furthermore, as expected, GAD65/67 immunoreactivity does not overlap with the nuclear Dlx2 staining (Fig. 1C). All EGFP ${ }^{+}$neuronal cells analyzed displayed high frequency of firing (Fig. $1 D, E$ ) (maximal firing fre-
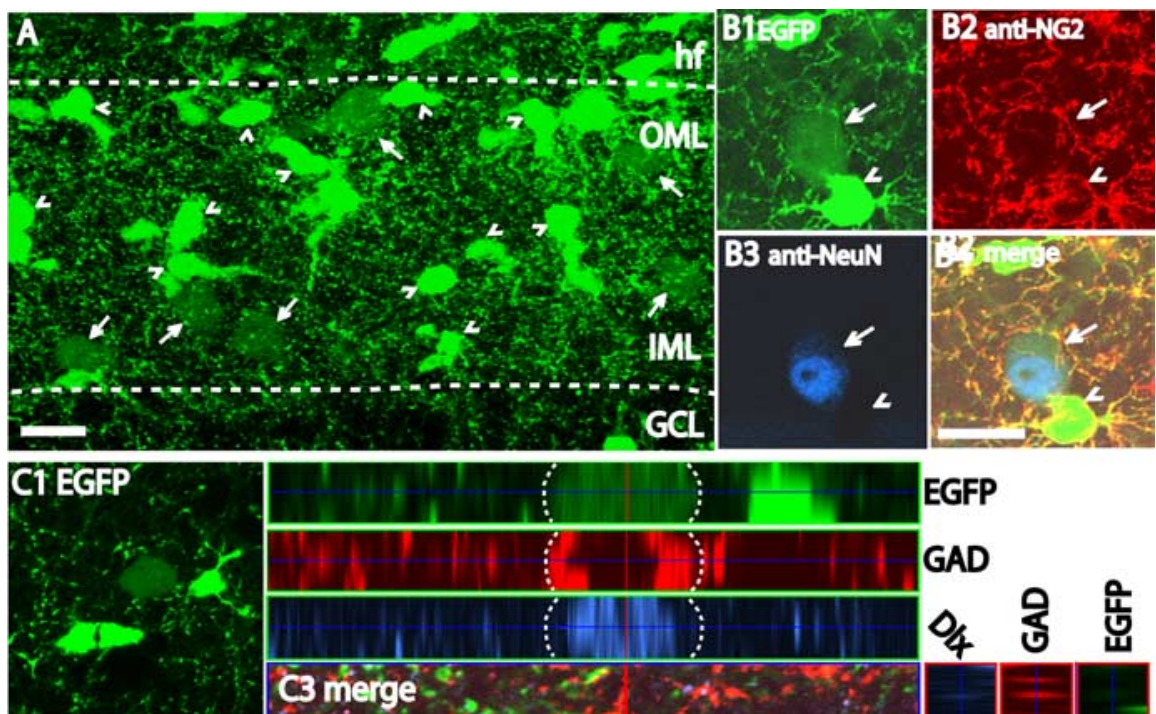

EGFP
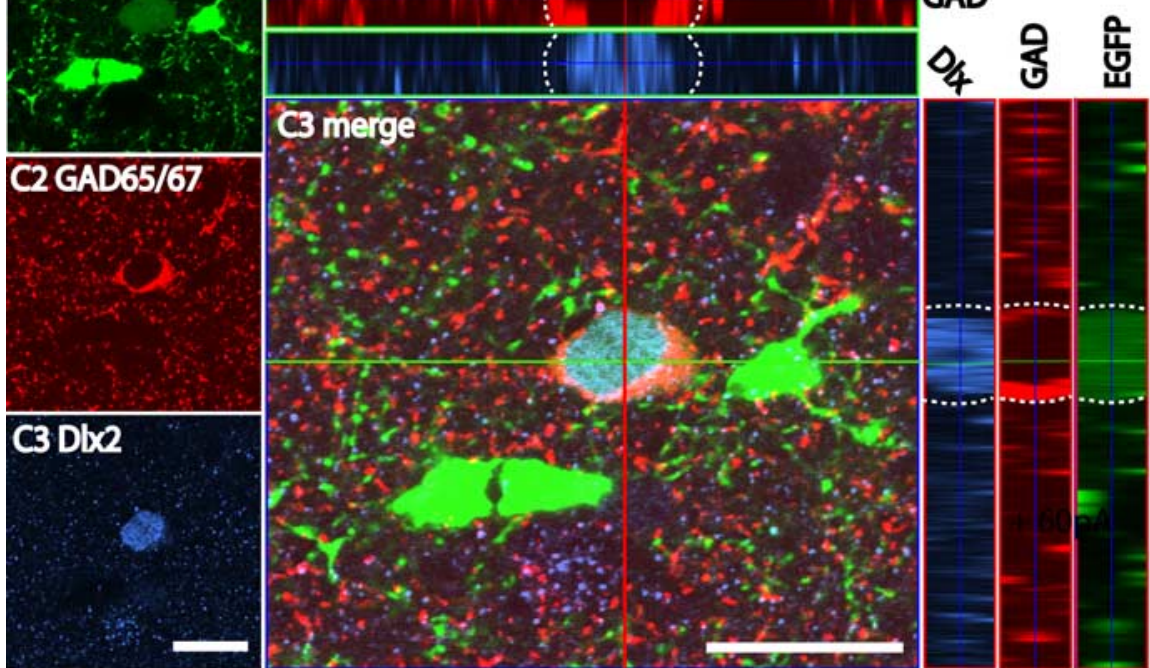

D
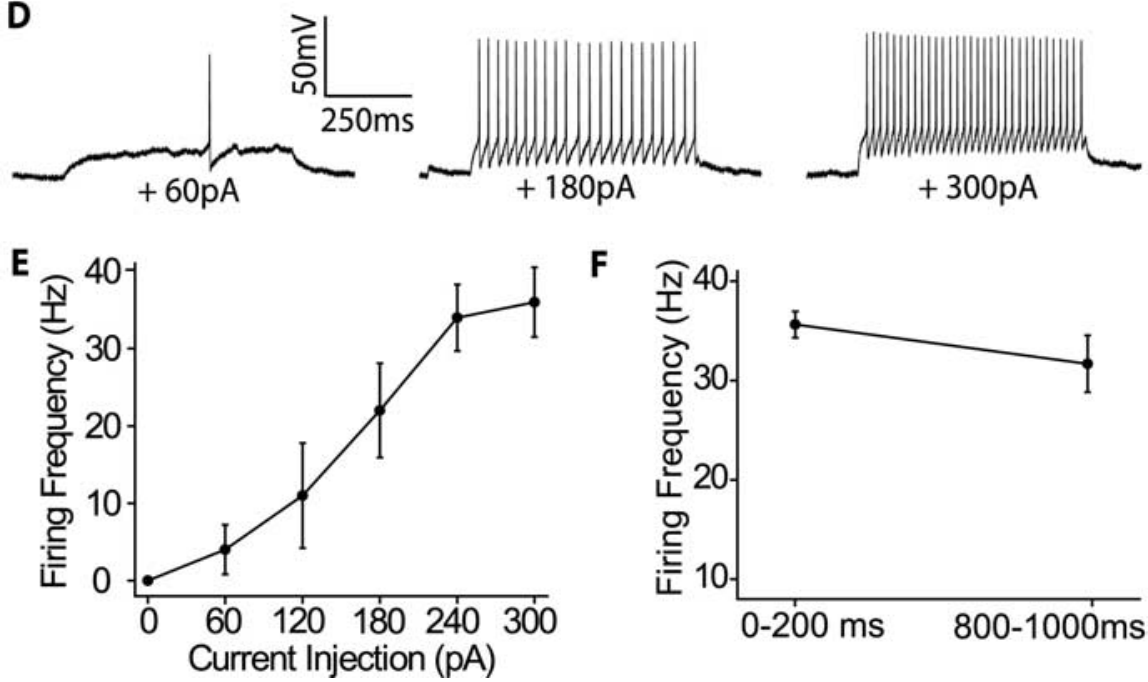

Figure 1. The CNP-EGFP mouse permits identification of developing GABAergic interneurons in the early postnatal ML. $\boldsymbol{A}$, Bright EGFP ${ }^{+}$, small, irregularly shaped cells (arrowheads) and fainter EGFP ${ }^{+}$, larger round/ovoid-shaped cells (arrows) are present throughout the ML. $\boldsymbol{B}$, The bright EGFP ${ }^{+}$cells correspond to NG2 ${ }^{+}$CNP gene-expressing progenitors (arrowhead), whereas faint EGFP ${ }^{+}$cells are NeuN ${ }^{+}$neurons (arrow). C, Stacked confocal images with corresponding orthogonal reconstruction demonstrate that these neurons are developing interneurons, based on GAD65/67 and DIx2 expression. D, E, Eliciting action potential firing in response to varying current injections demonstrates a fast-spiking phenotype. $\boldsymbol{F}$, No statistical difference was noted between the firing frequency in the first and last 200 ms epochs of a 1000 ms depolarizing 300 pA current injection. No statistical differences in any of the measured parameters were noted between $0 \mathrm{ML}$ and IML EGFP ${ }^{+}$neurons, and hence data were pooled. hf, Hippocampal fissure. Scale bars, $50 \mu \mathrm{m}$. 
quency at $300 \mathrm{pA}$ current injection $=36.5 \pm 4.5 \mathrm{~Hz} ; n=18$; range, $26-43 \mathrm{~Hz}$ ). Furthermore, action potentials possessed deep fast afterhyperpolarizations (Fig. 1D) (fast afterhyperpolarization amplitude $=-17.9 \pm 0.7 \mathrm{mV}$ ). All cells displayed minimal slowing of firing frequency during a $300 \mathrm{pA}$ depolarizing current injection for $1000 \mathrm{~ms}$ (Fig. $1 F$ ). These functional characteristics together with our immunocytochemical analyses clearly demonstrate that $\mathrm{EGFP}^{+}$neurons in the $\mathrm{OML}$ and IML are GABAergic interneurons.

Immunostaining indicated calretinin-positive $\left(\mathrm{CR}^{+}\right)$cell bodies primarily in the OML, in addition to a dense plexus of $\mathrm{CR}^{+}$immunoreactivity in the IML (supplemental Fig. $1 A-C$, available at www.jneurosci.org as supplemental material). The latter corresponds to the termination zone of CR-containing excitatory hilar mossy cell afferents that form the associational/ commissural pathway (Liu et al., 1996). Conversely, calbindinpositive $\left(\mathrm{CB}^{+}\right)$cell bodies were mainly confined to the IML/GCL border (supplemental Fig. $1 D, E$, available at www.jneurosci.org as supplemental material). $\mathrm{CR}^{+}$or $\mathrm{CB}^{+}$cells never expressed EGFP (supplemental Fig. $1 B, C, E$, available at www.jneurosci.org as supplemental material). Parvalbumin or somatostatin immunoreactivity was not observed in the ML at P9 (supplemental Fig. $2 A, B, D, E$, available at www.jneurosci.org as supplemental material), although cells expressing detectable levels of these proteins were identified in CA1/CA3 regions of the hippocampus (supplemental Fig. 2C,F, available at www.jneurosci.org as supplemental material). Finally, cholecystokinin immunostaining with three separate antibodies was performed (see supplemental Table 1, available at www.jneurosci.org as supplemental material), but we obtained variable and unreliable staining in mouse tissue at this age (data not shown).

We compared basic membrane parameters between $\mathrm{EGFP}^{+} \mathrm{Dlx} 2{ }^{+} \mathrm{NeuN}^{+} \mathrm{GAD} 65 / 67^{+}$interneurons whose cell bodies were positioned either in the OML or IML. IML interneurons displayed significantly lower input resistance values than their OML counterparts (supplemental Fig. $3 A, B$, available at www. jneurosci.org as supplemental material). Consistent with this finding, IML interneurons also possessed a more hyperpolarized resting membrane potential than OML interneurons (supplemental Fig. 3C, available at www.jneurosci.org as supplemental material). Such changes in passive membrane properties are reminiscent of those that occur during neuronal maturation (Liu et al., 2000; Grabauskas and Bradley, 2001). Therefore, the use of the CNP-EGFP mouse allows physiological analysis of different developmental stages of the same neuronal population.

\section{Evoked excitatory transmission onto developing OML and IML interneurons}

We evoked AMPA receptor-mediated responses in OML and $\mathrm{IML} \mathrm{EGFP}^{+}$interneurons by perforant path stimulation (Fig. $2 A$ ). A single monosynaptic EPSC was noted in almost all (11 of 12) OML interneurons tested (Fig. 2B) and therefore likely arises directly from the perforant path. In contrast, perforant path activation always ( 9 of 9 cells) resulted in a presumed monosynaptic response followed by number of asynchronous EPSCs in IML interneurons (Fig. $2 B$ ). Addition of $10 \mu \mathrm{M}$ gabazine (GBZ) had no effect on the evoked EPSCs in OML interneurons (Fig. 2C). In contrast, GBZ resulted in the emergence of a large barrage of EPSCs in IML interneurons (Fig. 2C). These observations were confirmed by pretreating slices with $50 \mu \mathrm{M}$ picrotoxin for $15 \mathrm{~min}$ before evoking EPSCs in the OML and IML interneurons (Fig. $2 D)$. Thus, a large component of evoked synaptic input in IML interneurons is only evident after removal of $\mathrm{GABA}_{\mathrm{A}}$ receptormediated inhibition.

In all cases in which disinhibition was induced pharmacologically, evoked responses in IML interneurons displayed an initial EPSC temporally very close to the stimulus artifact (Fig. $2 C, D$, arrows), followed by the characteristic barrage of responses. To ascertain whether this short-latency EPSC was in fact monosynaptic and therefore originating from the perforant path, we isolated evoked NMDA receptor-mediated responses in the absence and presence of $10 \mu \mathrm{M}$ CNQX (Fig. 2E). As expected, in OML interneurons that only displayed a single EPSC after perforant path activation, a clear NMDA receptor-mediated outward current was observed even after addition of CNQX, confirming that this response was indeed monosynaptic (Fig. $2 E$ ). Interestingly, in IML interneurons, only an evoked NMDA receptor-mediated response that was temporally coincident with the short-latency AMPA receptor EPSC remained after the addition of CNQX (Fig. $2 E$, arrowhead and arrow). Thus, we conclude that this initial EPSC was indeed monosynaptic and arises directly from the perforant path, whereas the delayed barrage corresponds to polysynaptic responses.

Even high stimulation intensities failed to evoke EPSCs in OML interneurons after stimulation in the CA3 region (Fig. $2 F$ ). In contrast, CA3 stimulation elicited asynchronous EPSCs in IML interneurons (Fig. 2 F). GBZ application revealed a barrage of EPSCs (Fig. $2 F$ ) in a similar manner to that seen after perforant path stimulation (Fig. 2C,D). Finally, the dendritic fields of developing OML and IML interneurons are clearly nonoverlapping (Fig. 2G,H). Thus, OML interneurons possess dendrites located in the OML (Fig. 2G), whereas IML interneuron dendrites are found in the medial ML (MML), the IML, and the hilar region (Fig. $2 H$ ).

\section{Inhibition of excitatory transmission onto developing OML and IML interneurons by activation of group II and III metabotropic glutamate receptors}

It is well established that afferents from excitatory entorhinal cortical neurons are divided into the lateral perforant path (LPP) and medial perforant path (MPP), which terminate in the OML and MML, respectively. Immunocytochemical and physiological analyses have previously shown that glutamatergic transmission from MPP and LPP onto excitatory dentate granule cells, which have dendritic fields spanning the entire ML, are specifically inhibited by group II and III presynaptic metabotropic glutamate receptors (mGlus), respectively (Macek et al., 1996). Because OML interneurons only possess dendrites in the OML, not in the MML, and the opposite is true for IML interneurons (Fig. 2G,H), we wanted to determine whether these pharmacologically distinct modulatory mechanisms are apparent in the previously identified perforant path inputs. The group II mGlu agonist $2 S, 2^{\prime} R, 3^{\prime} R-2-\left(2^{\prime}, 3^{\prime}\right.$-dicarboxycyclopropyl)glycine (DCG-IV) had minimal effect on the evoked monosynaptic EPSC peak in OML interneurons but significantly inhibited the monosynaptic EPSC peak in IML interneurons (Fig. $3 A, B$ ). Conversely, the group III agonist $\mathrm{L}(+)$-2-amino-4-phosphonobutyric acid (LAP4) significantly inhibited the monosynaptic EPSC peak in IML interneurons but did not modulate the evoked monosynaptic EPSC peak in OML interneurons (Fig. 3C,D). These findings demonstrate that synaptic inputs to OML and IML interneurons from the entorhinal cortex via the perforant paths are under presynaptic inhibitory modulation by different subtypes of presynaptic mGlus (Fig. 3E), which is very likely a result of the observed 
differing dendritic fields in these developmentally linked interneurons.

The data were reanalyzed to ascertain the relative effects of DCG-IV on the monosynaptic and polysynaptic EPSC responses in IML interneurons, by calculating the charge transferred during these two components. DCG-IV-mediated inhibition of the monosynaptic AMPA receptormediated charge transfer in IML interneurons yielded quantitatively similar results to those seen with the EPSC peak measurements (Fig. 3, compare $B, F$ ). Interestingly, DCG-IV potently and completely abolished all of the polysynaptic EPSC responses in IML interneurons (Fig. $3 A, F$ ), suggesting the involvement of mossy fibers in the EPSC barrage after perforant path stimulation.

\section{Inhibitory transmission onto}

developing OML and IML interneurons Although $\mathrm{GABA}_{\mathrm{A}}$ receptor-mediated miniature IPSCs (mIPSCs) were detected in OML and IML interneurons, a number of differences were apparent (Fig. 4; supplemental Table 2, available at www. jneurosci.org as supplemental material). First, the average mIPSC amplitude and frequency was significantly greater in OML interneurons (Fig. 4A; supplemental Table 2, available at www.jneurosci.org as supplemental material). The former difference was attributable to the presence of larger mIPSC events (>50 pA) (Fig. $4 A-C)$ in OML interneurons. As assessed by $r^{2}$ values, a single-exponential fit adequately described the MIPSC decay in IML interneurons (Fig. 4D). However, the mIPSC decay in OML interneurons was significantly better fit with two exponentials (Fig. 4D; supplemental Table 2, available at www.jneurosci.org as supplemental material). In OML interneurons, the relative proportion of mIPSC decays was calculated as $76.2 \pm 5.9$ and $23.7 \pm 5.8 \%$ for the fast and slow components, respectively, and the weighted time constant was calculated as $20.9 \pm 7.4 \mathrm{~ms}$, which was not found to be statistically different from the mIPSC decay time constant in IML interneurons (16.9 \pm 1.4 ) (supplemental Table 2 , available at www.jneurosci.org as supplemental material). Application of GBZ had no significant effect on holding current values in either OML or IML interneurons, suggesting lack of a tonic $\mathrm{GABA}_{\mathrm{A}}$ receptordependent current (data not shown).

Using cell-attached patches, it was evident that throughout the developmental period tested (P6-P12), bath application of muscimol caused depolarization of OML interneurons but produced minimal
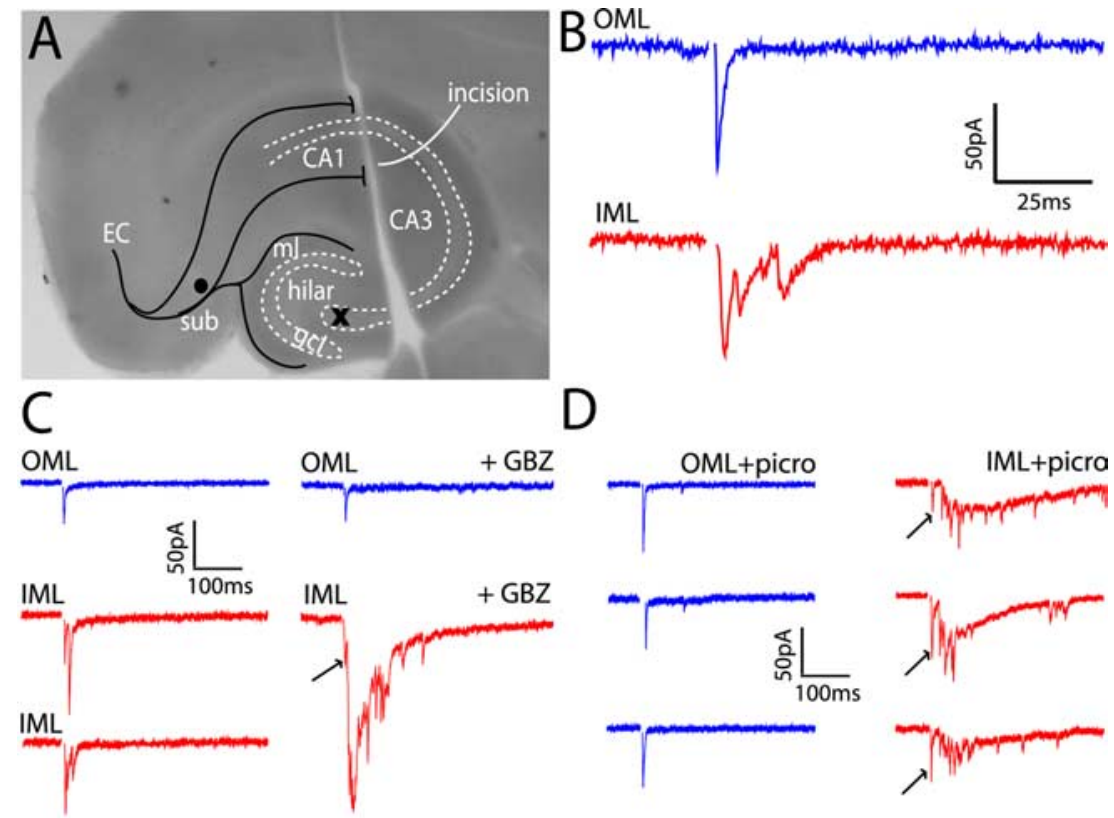

E омь
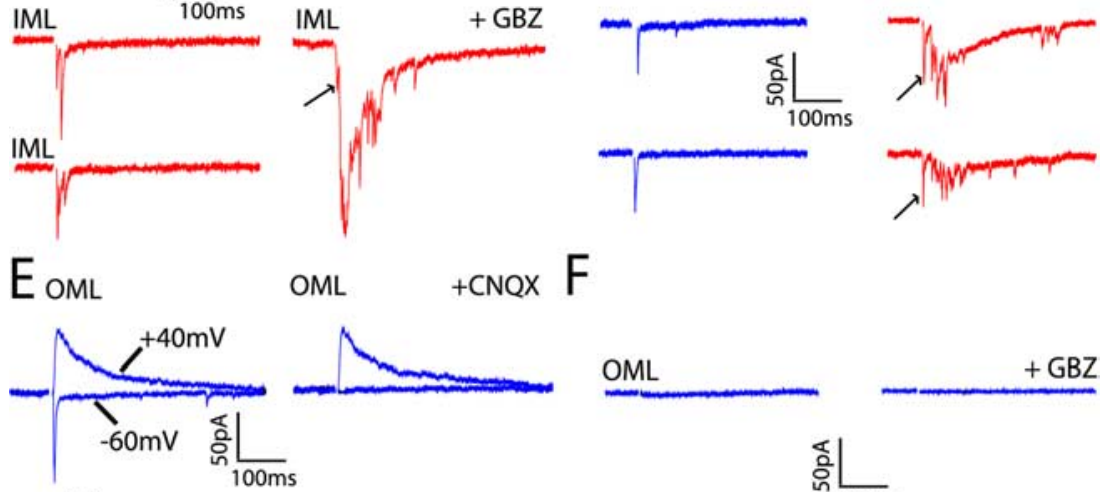

OML

+ CNQX

$\mathrm{F}$

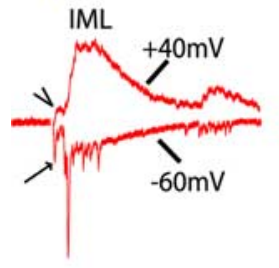

IML

+ CNQX

OML $+\mathrm{GBZ}$
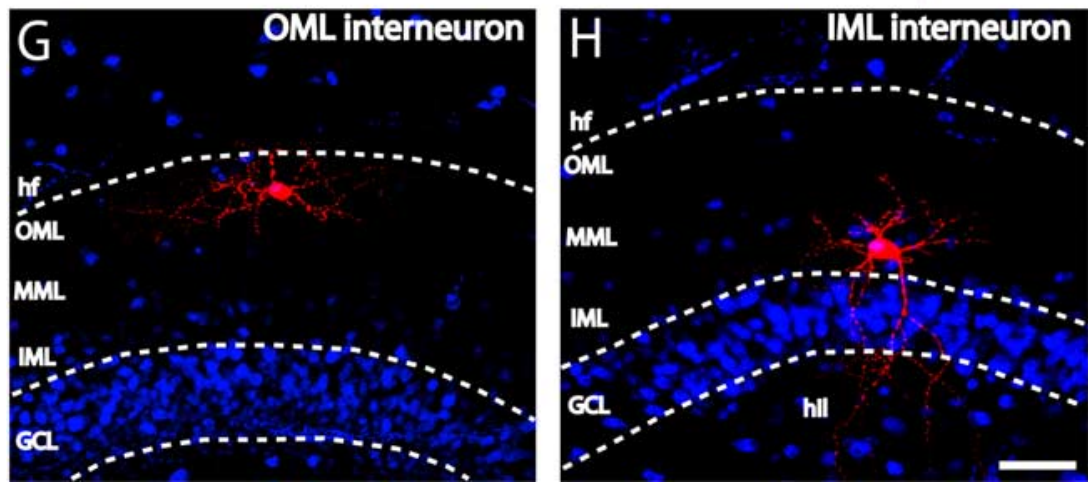

Figure 2. OML and IML interneurons are differentially integrated into the excitatory hippocampal circuitry as a consequence of dendritic field reorganization. $\boldsymbol{A}$, EPSCs in OML and IML interneurons were evoked by subicular (perforant paths; filled circle) or CA3 pyramidal layer (cross) stimulation. In all experiments, an incision was made between the CA1 and CA3. All blue and red traces denote evoked responses from $0 M L$ and IML, respectively. $B$, Subicular stimulation elicits a monosynaptic EPSC response in $0 M L$ interneurons but results in a "flurry" of asynchronous EPSCs in IML interneurons. C, Addition of $10 \mu \mathrm{M}$ GBZ has no effect on the evoked EPSC response in OML interneurons but results in a large barrage of EPSCs in IML interneurons. Traces on the right are 3-5 min after addition of GBZ. D, Similar results are attained after preincubation of slices with $50 \mu \mathrm{m}$ picrotoxin (picro). C, D, Arrows highlight the presence of initial EPSC that is temporally very close to the stimulus. $\boldsymbol{E}, 0 \mathrm{ML}$ interneurons display an NMDA receptor-mediated outward EPSC, even after the application of $10 \mu \mathrm{M}$ CNQX, indicating that the response is monosynaptic. In IML interneurons, an outward NMDA receptor-mediated response is observed that is temporally coincident with the initial inward AMPA receptor-mediated EPSC (arrowhead and arrow). This is followed by a barrage of AMPA receptor-mediated EPSCs with corresponding NMDA receptor currents. After CNQX application, only the NMDA receptor response (arrowhead) that was temporally coincident with the initial AMPA receptor response remained, indicating that this was indeed monosynaptic. $F$, CA3 stimulation in the presence of GBZ elicited no response in OML interneurons, but an EPSC profile similar to that seen after perforant path stimulation (in absence and presence of GBZ) was noted in IML interneurons. $\mathbf{G}, \boldsymbol{H}$, Biocytin filling of $0 \mathrm{ML}$ and IML interneurons shows distinct nonoverlapping dendritic fields. EC, Entorhinal cortex; hf, hippocampal fissure; hil, hilar region; sub, subiculum. Scale bar, $50 \mu \mathrm{m}$. 
A

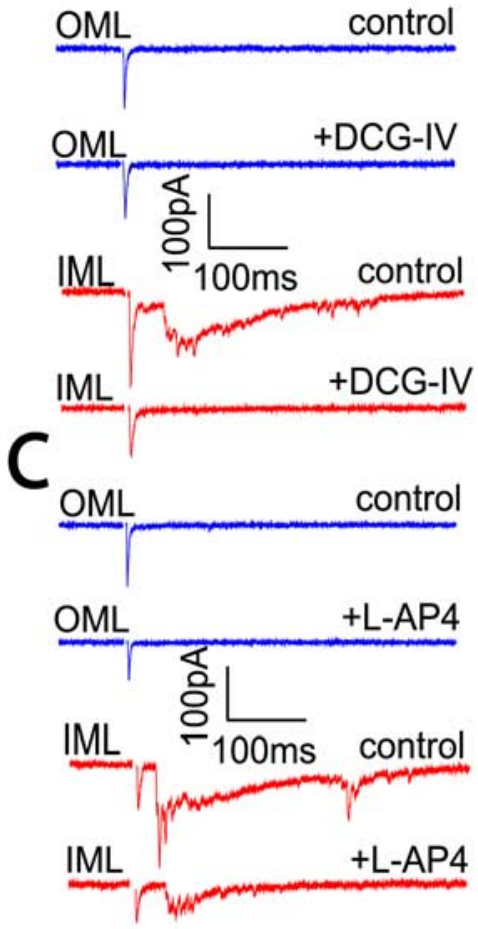

Time (mins)

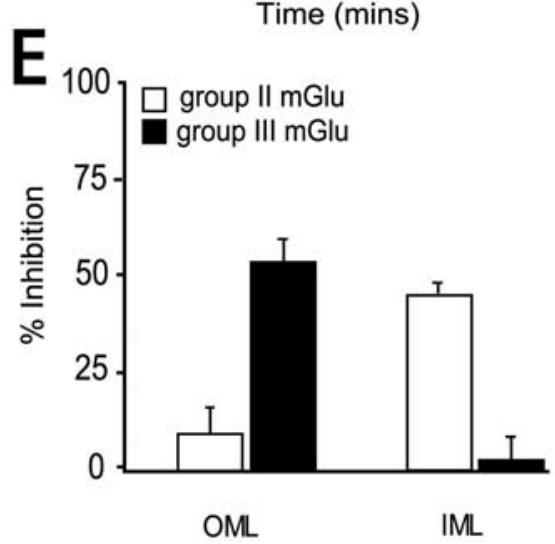

Figure 3. Selective inhibition of monosynaptic perforant path transmission by group II and III mGlus in IML and OML developing interneurons, respectively. All blue and red traces denote evoked EPSC responses from OML and IML, respectively. A, B, DCG-IV inhibits AMPA receptor-mediated monosynaptic EPSC peak responses after perforant path stimulation in IML but not OML interneurons. $C, D, L-A P 4$ inhibits the AMPA receptor-mediated monosynaptic EPSC peak responses after perforant path stimulation in OML but not IML interneurons. $E$, Bar graph illustrating differential inhibition by group II (open bars) and group III (filled bars) mGlu activation on the perforant path evoked EPSCs in OML and IML interneurons. $\boldsymbol{F}$, In IML interneurons, DCG-IV inhibits the charge transferred by the monosynaptic response in a quantitatively similar manner to that noted with EPS (peak measurements (red filled circles in $\boldsymbol{F}$ vs red filled circles in $\boldsymbol{B})$. DCG-IV totally abolishes the charge transferred by the EPSC barrage $(\boldsymbol{A} ; \boldsymbol{F}$, open red circles). Data are means \pm SEM from five to six OML and IML interneurons.

effect on the membrane potential of IML interneurons (Fig. $4 E, F)$. This absence of effect cannot be attributed to the possible lack of $\mathrm{GABA}_{\mathrm{A}}$ receptor expression in IML interneurons, because our mIPSC data clearly demonstrate synaptic activation of these receptors (Fig. $4 A$ ). We conclude that $\mathrm{GABA}_{\mathrm{A}}$ receptor activation leads to a depolarizing response on developing OML interneurons but a shunting response in IML interneurons.

\section{Discussion}

CNP gene-expressing progenitors give rise to both oligodendrocytes and interneurons (Belachew et al., 2003; Aguirre et al.,
2004). The OML and IML interneurons analyzed in this current study express EGFP, indicating that they are both derived from CNP gene-expressing progenitors. These interneurons eventually lose EGFP expression as they mature (Belachew et al., 2003); therefore, the fact that the IML and OML interneurons studied here still express detectable levels of EGFP suggests that they have not yet reached a fully mature state. We also demonstrate that almost all EGFP ${ }^{+}$interneurons express Dlx2 at the ages tested. This transcription factor is intimately involved in interneuron migration and differentiation (Anderson et al., 1999; Pleasure et al., 2000) and is downregulated in neocortical interneurons during postnatal development (Cobos et al., 2006). This lends additional evidence to suggest that the ML interneurons examined in the current study are still undergoing developmental maturation during this postnatal period. The finding that interneurons lack detectable levels of several subtype-specific markers further supports this hypothesis.

In the current study, cell-counting analyses show a positional shift, as highlighted in the ratio of OML/IML EGFP ${ }^{+}$ interneuron numbers at P6 versus $\mathrm{P} 12$ ( $2.2 \pm 0.5$ vs $0.3 \pm 0.1$; five to seven sections from three independent animals at each age). Furthermore, very few interneurons are present in the adult ML (Freund and Buzsaki, 1996), suggesting that the majority found in this area during the early postnatal periods are not at their final anatomical destination. These observations, together with direct evidence demonstrating migration of interneuron populations from the OML to the IML in the early postnatal hippocampus (Morozov and Freund, 2003; Morozov et al., 2006), lead us to conclude that the CNPEGFP mouse allows identification of developing ML interneurons that are undergoing this migratory program.

Our study shows that developing ML interneurons receive functional glutamatergic and GABAergic synaptic inputs, as alluded to by previous anatomical data (Morozov et al., 2006). However, varying aspects of this signaling differ as interneurons migrate from the OML to the IML. A reorganization in the dendritic fields during migration is a major factor underlying the differences noted in synaptic innervation by glutamatergic afferents. To summarize (supplemental Fig. 4, available at www. jneurosci.org as supplemental material), IML interneurons primarily possess dendrites in the OML, and therefore the majority of their excitatory input is via the LPP in a forward manner from the entorhinal cortex. In contrast, IML interneurons possess dendrites in the MML, IML, and hilar regions. This enables these interneurons to receive not only monosynaptic inputs via the 

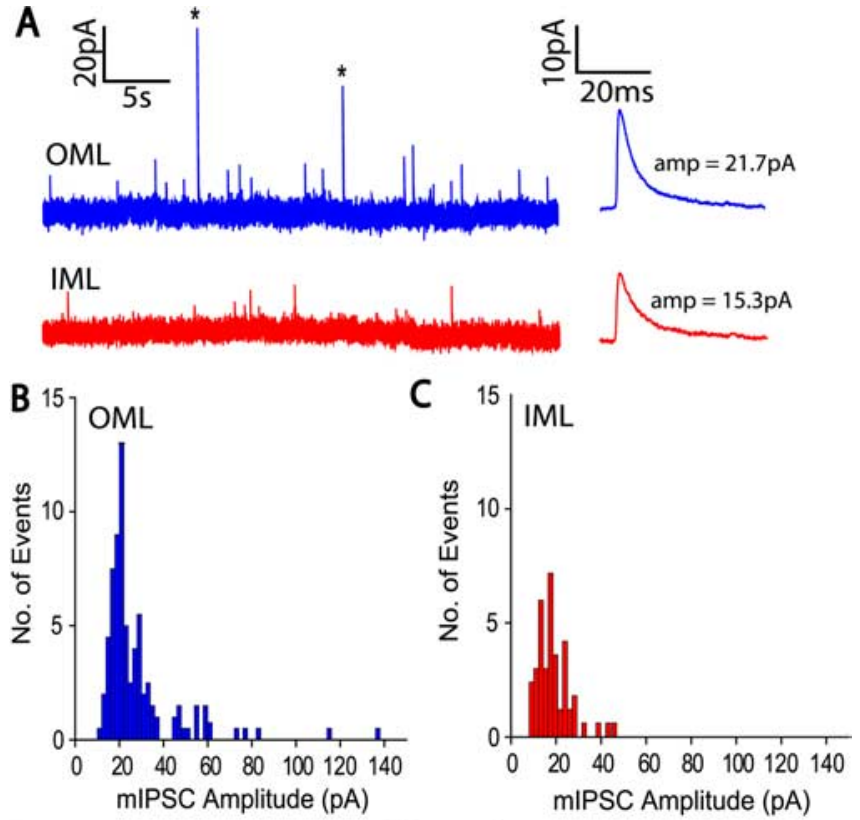

D1 OML
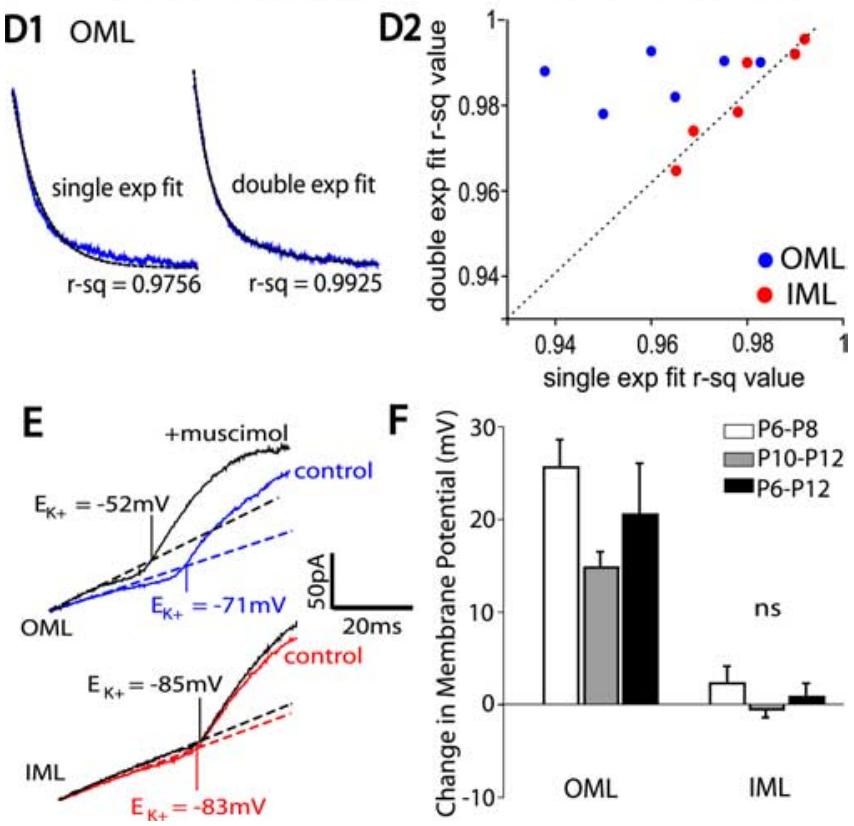

Figure 4. Differences in $\mathrm{GABA}_{\mathrm{A}}$ receptor-mediated innervation of developing $0 \mathrm{ML}$ and $\mathrm{IML}$ interneurons. All blue and red traces denote evoked EPSC responses from $0 M L$ and $I M L$, respectively. $\boldsymbol{A}$, Representative traces illustrating outward mIPSC events in OML and IML interneurons plus an ensemble average of all mIPSC events. $\boldsymbol{B}, \boldsymbol{C}$, Representative frequency distribution histograms of mIPSC amplitude from an OML and IML interneuron. The presence of largeramplitude mIPSCs ( $>50 \mathrm{pA}$ ) in the $0 \mathrm{ML}$ interneuron (see $\boldsymbol{A}$, asterisks) are never observed in IML interneurons. $\boldsymbol{D}$, mIPSC decay kinetics differ between $0 \mathrm{ML}$ and IML interneurons. In OML interneurons, a double-exponential is statistically better than a single-exponential fit (black lines depict the exponential fit superimposed on the blue EPS( decay), as assessed by $r^{2}$ coefficient values (D2). In contrast, a single-exponential fit adequately describes the mIPSC decay in IML interneurons (D2). Average data for mIPSC amplitude, frequency, and decay values are summarized in supplemental Table 2 (available at www.jneurosci.org as supplemental material). $\boldsymbol{E}$, Using a cell attached protocol (see supplemental methods, available at www.jneurosci.org as supplemental material), activation of $\mathrm{GABA}_{\mathrm{A}}$ receptors by muscimol depolarizes $0 \mathrm{ML}$ interneurons (top; blue vs black trace) but has minimal effect in IML interneurons (bottom; red vs black trace). $\boldsymbol{F}$, Summary graph depicting the average effect in $0 M L$ and IML interneurons. Data were pooled according to three different criteria based on the range of developmental ages at which the experiments were performed. Data are means \pm SEM from four to eight OML and IML interneurons. amp, Amplitude; No., number; exp, exponential; ns, not significant.
MPP, but also a number of polysynaptic responses arising from complex recurrent interactions between granule cells, mossy cells, and CA3 pyramidal cells that occur after disinhibition. Thus, OML interneurons process information by receiving a combination of forward and recurrent signals.

In addition to excitatory drive, developing ML interneurons also receive inhibitory innervation. We demonstrate a number of differences in MIPSC parameters between OML and IML interneurons. It remains unclear as to the physiological significance, but these changes clearly reflect modifications in $\mathrm{GABA}_{\mathrm{A}}$ receptor-mediated transmission as OML interneurons migrate to the IML. Developmental plasticity in subunit composition of $\mathrm{GABA}_{\mathrm{A}}$ receptors may underlie the changes noted in mIPSC decay and synaptic strength (Ortinski et al., 2004). Interestingly, it has been demonstrated that in the immature hippocampus and barrel cortex, $\mathrm{GABA}_{\mathrm{A}}$ receptor activation results in depolarization of excitatory neurons, which during postnatal development changes to a hyperpolarizing response (Ben Ari, 2002; Daw et al., 2007). Here, we demonstrate that $\mathrm{GABA}_{\mathrm{A}}$ receptor responses are depolarizing in developing OML interneurons. Previous studies have linked the depolarizing effects of GABA on neuronal progenitor and immature neurons with the processes of migration, differentiation, synaptogenesis, and the development of circuit function (Ben Ari, 2002; Owens and Kriegstein, 2002; PangratzFuehrer et al., 2007). Hence, depolarizing actions of $\mathrm{GABA}_{\mathrm{A}}$ receptor activation on OML interneurons may play an important role in their appropriate development. As OML interneurons migrate toward the IML, $\mathrm{GABA}_{\mathrm{A}}$ receptor activation becomes primarily shunting. In contrast to excitatory neurons, experimental evidence suggests that $\mathrm{GABA}_{\mathrm{A}}$-mediated inhibition in mature interneurons remains predominantly shunting (Martina et al., 2001; Bartos et al., 2002; Banke and McBain, 2006). Thus, our data demonstrate that migrating ML interneurons undergo alterations in inhibitory innervation, which likely reflect a switch from a predominantly developmental signal (depolarizing response) to one that is more in line with $\mathrm{GABA}_{\mathrm{A}}$ receptor function (shunting inhibition) in the mature hippocampus.

In conclusion, the CNP-EGFP transgenic mouse permits functional analysis of developing ML interneurons. Using this mouse, we were able to reveal that ML interneurons undergo a series of prominent synaptic changes during migration from OML to IML. A full understanding of interneuron synaptic integration during early postnatal life is an important first step in determining the causes of acute and chronic neurological scenarios that may arise as a result of their improper migration through the ML of the developing hippocampus.

\section{References}

Aguirre AA, Chittajallu R, Belachew S, Gallo V (2004) NG2-expressing cells in the subventricular zone are type C-like cells and contribute to interneuron generation in the postnatal hippocampus. J Cell Biol 165:575-589.

Anderson S, Mione M, Yun K, Rubenstein JL (1999) Differential origins of neocortical projection and local circuit neurons: role of Dlx genes in neocortical interneuronogenesis. Cereb Cortex 9:646-654.

Banke TG, McBain CJ (2006) GABAergic input onto CA3 hippocampal interneurons remains shunting throughout development. J Neurosci 26:11720-11725.

Bartos M, Vida I, Frotscher M, Meyer A, Monyer H, Geiger JR, Jonas P (2002) Fast synaptic inhibition promotes synchronized gamma oscillations in hippocampal interneuron networks. Proc Natl Acad Sci USA 99:13222-13227.

Belachew S, Chittajallu R, Aguirre AA, Yuan X, Kirby M, Anderson S, Gallo V (2003) Postnatal NG2 proteoglycan-expressing progenitor cells are in- 
trinsically multipotent and generate functional neurons. J Cell Biol 161:169-186.

Ben Ari Y (2002) Excitatory actions of gaba during development: the nature of the nurture. Nat Rev Neurosci 3:728-739.

Chittajallu R, Aguirre A, Gallo V (2004) NG2-positive cells in mouse white and grey matter display distinct physiological properties. J Physiol (Lond) 561:109-122.

Chittajallu R, Aguirre AA, Gallo V (2005) Downregulation of plateletderived growth factor- $\alpha$ receptor-mediated tyrosine kinase activity as a cellular mechanism for $\mathrm{K}^{+}$-channel regulation during oligodendrocyte development in situ. J Neurosci 25:8601-8610.

Cobos I, Long JE, Thwin MT, Rubenstein JL (2006) Cellular patterns of transcription factor expression in developing cortical interneurons. Cereb Cortex 16 [Suppl 1]:i82-i88.

Daw MI, Ashby MC, Isaac JT (2007) Coordinated developmental recruitment of latent fast spiking interneurons in layer IV barrel cortex. Nat Neurosci 10:453-461.

Dupuy-Davies S, Houser CR (1999) Evidence for changing positions of GABA neurons in the developing rat dentate gyrus. Hippocampus 9:186-199.

Freund TF, Buzsaki G (1996) Interneurons of the hippocampus. Hippocampus 6:347-470.

Grabauskas G, Bradley RM (2001) Postnatal development of inhibitory synaptic transmission in the rostral nucleus of the solitary tract. J Neurophysiol 85:2203-2212.

Liu X, Tilwalli S, Ye G, Lio PA, Pasternak JF, Trommer BL (2000) Morphologic and electrophysiologic maturation in developing dentate gyrus granule cells. Brain Res 856:202-212.

Liu Y, Fujise N, Kosaka T (1996) Distribution of calretinin immunoreactivity in the mouse dentate gyrus. I. General description. Exp Brain Res 108:389-403.
Macek TA, Winder DG, Gereau RW, Ladd CO, Conn PJ (1996) Differential involvement of group II and group III mGluRs as autoreceptors at lateral and medial perforant path synapses. J Neurophysiol 76:3798-3806.

Martina M, Royer S, Pare D (2001) Cell-type-specific GABA responses and chloride homeostasis in cortex and amygdala. J Neurophysiol 86:2887-2895.

Morozov YM, Freund TF (2003) Postnatal development and migration of cholecystokinin-immunoreactive interneurons in rat hippocampus. Neuroscience 120:923-939.

Morozov YM, Ayoub AE, Rakic P (2006) Translocation of synaptically connected interneurons across the dentate gyrus of the early postnatal rat hippocampus. J Neurosci 26:5017-5027.

Ortinski PI, Lu C, Takagaki K, Fu Z, Vicini S (2004) Expression of distinct alpha subunits of GABAA receptor regulates inhibitory synaptic strength. J Neurophysiol 92:1718-1727.

Owens DF, Kriegstein AR (2002) Is there more to GABA than synaptic inhibition? Nat Rev Neurosci 3:715-727.

Pangratz-Fuehrer S, Rudolph U, Huguenard JR (2007) Giant spontaneous depolarizing potentials in the developing thalamic reticular nucleus. J Neurophysiol 97:2364-2372.

Pleasure SJ, Anderson S, Hevner R, Bagri A, Marin O, Lowenstein DH, Rubenstein JL (2000) Cell migration from the ganglionic eminences is required for the development of hippocampal GABAergic interneurons. Neuron 28:727-740.

Plotkin JL, Wu N, Chesselet MF, Levine MS (2005) Functional and molecular development of striatal fast-spiking GABAergic interneurons and their cortical inputs. Eur J Neurosci 22:1097-1108.

Yuan X, Chittajallu R, Belachew S, Anderson S, McBain CJ, Gallo V (2002) Expression of the green fluorescent protein in the oligodendrocyte lineage: a transgenic mouse for developmental and physiological studies. J Neurosci Res 70:529-545. 